\title{
$9{ }^{\circ}$ Concurso Inovação na Gestão Pública Federal: idéias que fazem diferença
}

Por Christiane Telles, especial para a RSP

Para premiar e incentivar a geração e incorporação de novas práticas e conhecimentos na gestão pública, a ENAP e o Ministério do Planejamento, Orçamento e Gestão promovem, desde 1996, o Concurso Inovação na Gestão Pública Federal. Em 2004, os três primeiros colocados foram o Sistema Radar Comercial, do Ministério do Desenvolvimento, Indústria e Comércio Exterior (MDIC), o Sistema de Custos e Informações Gerenciais, do Banco Central (Bacen), e o Centro de Pesquisas do HCPA: Inovando a gestão da pesquisa, por meio de laboratórios compartilhados, do Hospital de Clínicas de Porto Aleg re (HCPA). A RSP conversou com as equipes vencedoras do $9^{\circ}$ Concurso Inovação na Gestão Pública Federal para relatar um pouco de suas experiências.

\section{$1^{\circ}$ colocado - Sistema Radar Comercial (MDIC)}

\section{Radar de oportunidades}

Em fevereiro deste ano, as exportações brasileiras atingiram US $\$ 7,7$ bilhões, volume suficiente para que, no acumulado de 12 meses (março de 2004 a fevereiro 2005), as exportações ultrapassassem a barreira dos US\$100 bilhões, resultado recorde na história do comércio exterior brasileiro.

Dados divulgados pelo Ministério do Desenvolvimento, Indústria e Comércio
Exterior (MDIC) mostram que, de janeiro a dezembro de 2004, o País exportou US\$ 96,475 bilhões, 32\% a mais que em 2003. A expansão das exportações foi inédita e significou geração adicional de divisas da ordem de US\$23,391 bilhões, além de um saldo na balança comercial de US\$ 33,696 bilhões. No mesmo período, o Brasil ampliou horizontes e passou também a vender para mercados "não-tradicionais" como Libéria, Sudão, Chipre, Estônia, Mauritânia e Tunísia.

Para atingir esse desempenho comercial histórico, uma parcela da contribuição vem de serviços que o MDIC disponibiliza pela internet como o "Aprendendo a exportar", o Portal do Exportador" e a "Vitrine do Exportador". Além deles, o Ministério dispõe de outra ferramenta: o Radar Comercial, que desde 2001 vem sendo implementado por uma equipe

Antonio José Gadelha Alves, Aristóteles Soares Benício, Giuseppe Gutemberg Gomes Dias, Luciana Fonseca Damasceno Vieira, Miguel Marques da Silva, Rogério Alencar Pereira de Sousa e Rosa de Lourdes Costa da Rocha

da Secretaria de Comércio Exterior (SECEX). O projeto, lançado oficialmente em abril de 2004, é um sistema que permite a identificação de oportunidades comerciais em 54 países, que representam aproximadamente $90 \%$ do comércio mundial. 


\section{O mapa da mina}

O Radar Comercial existia desde 2002 em versão impressa e suas informações davam suporte a diversas áreas do Ministério, especialmente àquelas responsáveis pela organização de missões comerciais no exterior. Agora, em versão eletrônica disponibilizada na internet (no endereço www.radarcomercial.desenvolvimento.gov.br), o acesso foi democratizado para uso de qualquer cidadão. Para acessar, o usuário precisa fazer um breve cadastro utilizando o CPF ou o CNPJ.

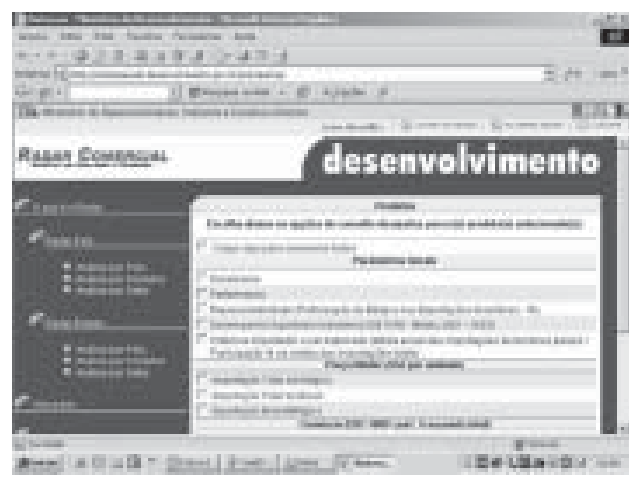

"Poderíamos dizer, sim, que é uma espécie de mapa da mina. Afinal, o Radar Comerial fornece informações fundamentais para quem quer saber para onde exportar e qual a melhor estratégia a ser utilizada. Vale a pena exportar roupas de cama para o Peru? Se pesquisarmos no Radar Comercial, vamos encontrar a resposta", afirma Aristóteles Soares Benício, Analista de Comércio Exterior que faz parte da equipe que desenvolveu e mantém o sistema.

O coordenador do projeto, Antônio José Gadelha Alves, ressalta ainda o pioneirismo do projeto: "Além de ser uma ferramenta muito poderosa e eficaz, não conhecemos nada semelhante. Foi totalmente desenvolvida pela equipe do ministério, para suprir um vácuo de infor mações e análises mercadológicas indispensáveis para otimizar os esforços para a exportação".

\section{Muito além das estatísticas}

"É importante frisar que o Radar Comercial não é apenas um fornecedor de estatísticas, mas, sim, um sistema que apresenta muito mais do que números, funcionando como instrumento de consulta e análise de dados relativos ao comércio exterior. O principal objetivo do Radar é auxiliar na seleção de mercados e produtos que apresentam maior potencialidade para o incremento das exportações brasileiras, seja a curto, médio e longo praz o", explica o coordenador do projeto.

O sistema é de fácil navegação e permite analisar cada mercado isoladamente, revelando em quais países o Brasil tem baixo market-share e, portanto, está explorando mal o potencial daquele mercado. A pauta importadora do país em foco é comparada com a pauta exportadora brasileira. Para análise mais aprofundada, são escolhidos os produtos que apresentam maior possibilidade de incremento das vendas brasileiras. "Para detectar, por exemplo, uma oportunidade de venda de calçados para a Ucrânia, é preciso saber o tipo: se é de couro ou de plástico, se é sapato, sandália, botina, etc. Enfim, saber em qual nicho de mercado está a oportunidade comercial, para que se possa incluir os produtores daquele nicho nos esforços de vendas (como missões

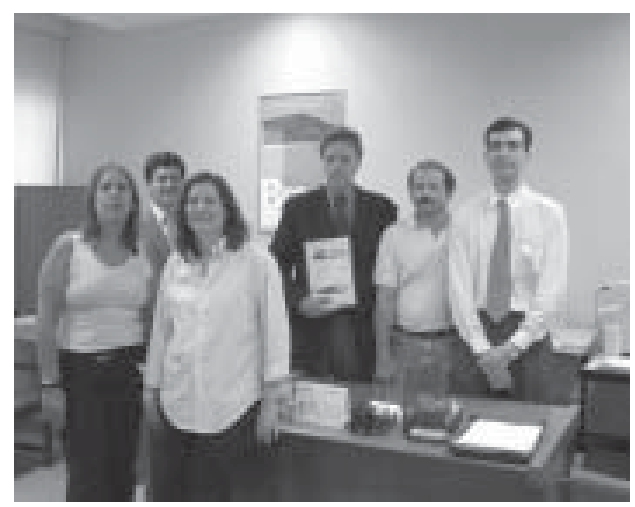

Uma parte da equipe do Radar Comercial 
comerciais e feiras) que possam ser realizadas naquele mercado", diz.

O Radar Comercial também informa para cada produto, em cada mercado, os países concorrentes e respectivas participações. Além disso, relaciona as medidas tarifárias e não-tarifárias de cada mercado, classifica cada produto quanto ao dinamismo das importações do país em estudo e quanto à performance das exportações brasileiras. "As pesquisas podem ter como foco o Brasil ou um estado brasileiro em relação a um determinado país ou em relação ao mundo. As análises relativas aos estados são de grande importância para subsidiar o planejamento do desenvolvimento regional", enfatiza Luciana Damasceno, que também compõe a equipe de analistas e é responsável pela elaboração de análises para os estados.

"Nós estamos preocupados em identificar os produtos para que essas análises possam contribuir não somente para a orientação dos programas de promoção comercial, mas também para o direcionamento dos investimentos voltados para a exportação. As análises do sistema são utilizadas para construção de estratégias de abordagens dos mercados internacionais", ressalta Gadelha.

\section{Potencial exportador}

As informações do Radar Comercial são utilizadas por empresas de pequeno, médio e grande porte. Mas as pequenas e médias, em especial, acabam sendo as mais beneficiadas. Os altos custos de uma pesquisa de mercado desencorajam boa parte dos empresários a buscar informações mais apuradas. Desse ponto de vista, o MDIC aposta nessa parcela que ainda não exporta para aumentar as cifras comerciais do país. Em 2003, essas empresas contribuíram com apenas 2,4\% das exportações brasileiras.

\section{Descobrindo o radar comercial}

Era a primeira vez que empresários do Estado do Acre participavam de um evento internacional de grande porte, mas eles estavam preparados para negociar. Antes de viajarem rumo à China, onde foi realizada a Expo Brasil-China em setembro de 2004, a comitiva acreana, composta por sete empresários, encontrou no Radar Comercial as informações que precisava para abrir espaço para seus produtos no imenso

\section{"Vale a pena exportar roupas de cama para $o$ Peru? Se pesquisarmos no Radar Comercial, vamos encontrar a resposta"}

mercado chinês, que em 2003, movimentou US\$ 800 bilhões na área de comércio exterior.

"As informações do Radar Comercial foram fundamentais para que nossos empresários pudessem ter uma visão mais real dos negócios que poderiam ser fechados com os chineses. Na palestra Oportunidades de Negócios Brasil China, que precedeu a viagem, os dados do Radar mostraram de forma precisa quais produtos deveriam ser negociados", afirma Leonardo Ferreira, Gerente de Relações Internacionais, da Secretaria de Planejamento e Desenvolvimento Econômico Sustentável do Estado do Acre.

Leonardo conta que o primeiro contato com o sistema aconteceu quando o Estado recebeu uma análise realizada pela equipe do Ministério sobre as possibilidades de negócios do Acre com os países andinos, em especial a Bolívia e 
o Peru, países fronteiriços. "Como era um material muito completo e continha uma quantidade muito grande de informações, fizemos disso um CD-ROM e disponibilizamos essas informações para os empresários locais. Esse foi o primeiro CD-ROM de inteligência comercial do país”, enfatiza Ferreira. Além desse CD, mais de 60 empresários foram capacitados para utilizarem o Radar Comercial na internet, por meio de uma ampla divulgação do sistema em todo o Estado.

"Atualmente, o Radar Comercial é uma ferramenta utilizada com freqüência pelos empresários acreanos. Pela importância que esse sistema representa para o incremento das nossas exportações, é nosso objetivo repassá-lo e instruir o empresário a usálo", finaliza Fer reira.

Em 2004, o Acre exportou US\$ 7,6 milhões e seus principais produtos são a madeira cerrada, a Castanha do Brasil e a madeira compensada. Para 2005, os esforços estão voltados para a oferta de novos produtos, como móveis, doces regionais e artesanato.

\section{$2^{\circ}$ colocado - Sistema de custos e informações gerenciais (Bacen)}

\section{Custo por atividade}

Qual é o custo de fazer a fiscalização do sistema financeiro? Quanto é gasto para fazer política monetária? Ou ainda, quanto é necessário para fazer o dinheiro chegar à sociedade? Essas são algumas das perguntas respondidas pelo Sistema de Custos e Informações Gerenciais do Banco Central, do Banco Central, que fornece aos gestores da instituição as informações sobre os custos administrativos de toda a sua estrutura organizacional. O diferencial desse sistema está justamente em identificar o custo de cada atividade executada, de forma profundamente detalhada.
Implementá-lo foi o desafio proposto por uma equipe do Departamento de

José Clóvis Batista Dattoli, Jefferson Moreira, Teofanes Araujo Acioli, Cleber Pinto dos Santos, Marisa Minzoni, Roridam Penido Duarte, Dimas Luis Rodrigues da Costa, Adalberto Felinto da Cruz Júnior, Carlos Alberto Correa, Edina Souza Costa Pinto, Victor Luiz Benites F. Alves, Wilson Emílio da Silva, Osmar Lourenço Peres, Renato de Mendonça Lopes, Theofanes Silva Rocha de Oliveira.

Planejamento e Orçamento (DEPLA) do Banco Central, a partir da necessidade de se aprimorar a gestão do banco e aumentar a transparência diante da sociedade. Assim, desde junho de 2003, o Sistema de Custos e Informacõoes Gerenciais oferece um amplo banco de dados, que disponibiliza as informações necessárias à gestão da instituição.

A necessidade de se implementar um sistema de custos foi discutida dentro do Banco Central por mais de dez anos e somente a partir de 2000 o projeto começou a se concretizar. Nesse período, a equipe encarregada da experiência viu, na promulgação da Lei Complementar n 101, de 2000, a Lei de Responsabilidade Fiscal, uma base legal que reforçou sua importância.

Incluído no Programa de Aperfeiçoamento dos Instrumentos de Atuação do Banco Central (PROAT), o projeto foi financiado pelo Banco Mundial e desenvolvido por servidores do Banco Central e consultores extemos. A partir de então, várias etapas foram superadas: planejamento, divulg ação e acompanhamento, definição de critérios, desenvolvimento de interfaces, desenvolvimento do sistema e, finalmente, a implementação da ferramenta.

\section{Funcionalidade, otimização e conhecimento \\ "O Sistema de Custos e Informações Gerenciais foi concebido para ser um}


instrumento de apoio à gestão. Ele permite maior apuração e análise ampla dos custos dos serviços, atividades e processos distribuídos pela estrutura do Banco Central. Assim, temos como gerenciar todas as unidades, subunidades, diretorias e gerências regionais", explica o coordenador do projeto e chefe do DEPLA, José Clóvis Dattoli.

Por meio desse sistema, é possível mapear toda a instituição e ter uma visão do conjunto e, simultaneamente, de cada unidade do Banco, facilitando a mensuração e o controle de cada atividade executada ou de algum projeto a ser iniciado. Seja na criação ou extinção de um departamento, no remanejamento ou contratação de funcionários ou na racionalização do uso de água, luz e telefone, o

\section{"Temos como gerenciar todas as unidades, subunidades, diretorias e gerências regionais"}

Sistema de Custos subsidia as atividades de planejamento e a elaboração do orçamento do Banco.

Essa metodologia, escolhida após pesquisa realizada pela equipe do projeto, é denominada "Custo por Atividade $A B C$ (Activity Based Costing)", que, segundo o coordenador do projeto, é pioneiro na Administração Pública Federal. "O método $A B C$ é pioneiro até mesmo entre os bancos centrais. Claro que todo Banco Central tem seus mecanismos, mas nenhum está usando uma ferramenta tão poderosa como essa que adotamos", orgulha-se Dattoli.
De acordo com ele, em missões do Banco Mundial, que financiou o projeto, representantes de diversos bancos centrais vieram ao Brasil conhecer o Sistema de Custo. Figuram na lista o Banco Central da Espanha, o Federal Reserve, o Banco Central dos Estados Unidos, e, mais recentemente, o Banco Central de Angola.

\section{Comprovando os benefícios}

O chefe-adjunto do Departamento de Supervisão Indireta do Banco Central, Gilson Baliana, é um dos servidores que comprovou os benefícios da implementação do sistema e utiliza esse instrumento para gerenciar sua equipe. "Essa ferramenta permite um gerenciamento melhor do tempo dos funcionários. Agora, eu posso verificar quanto tempo é gasto para executar cada tarefa, o que me permite planejar melhor a distribuição de pessoal e de atividades em todo o departamento. Além disso, eu posso mensurar, com mais precisão, quanto custa executar cada tarefa, o que podemos racionalizar, em função do custo maior ou menor que elas apresentem”, explica Baliana. Ele ressalta ainda que o sistema também permite maior segurança na hora de tomar decisões. "Com o Sistema de Custos, nós temos uma visão estratégica que nos permite tomar decisões mais aprofundadas".

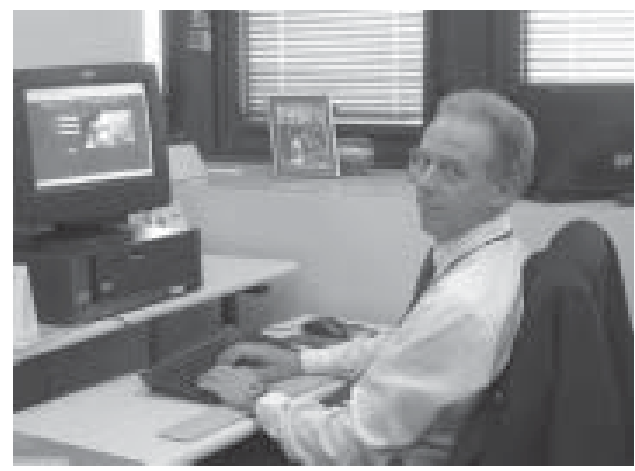

Gilson Baliana: sistema oferece visão estratégica 


\section{De olho no futuro}

O Sistema de Custo e Informações Gerenciais do Banco Central tem pouco mais de um ano e é considerado pela equipe do DEPLA um sistema bem mais amplo e com mais funcionalidades. "Com o decorrer do tempo, será gerada uma base histórica e, a partir daí, vamos poder comparar esses dados e chegar a outras conclusões, como, por exemplo, maior otimização de recursos, estabelecimento de metas de redução de custos e o desenvolvimento de indicadores de eficiência", explica Dattoli.

Agora, a equipe do projeto deseja que a iniciativa sirva de exemplo para outros órgãos da Administração Pública Federal: "Uma inovação traz enriquecimento institucional. Esperamos que o nosso caseseja exemplo para outras organizações", conclui.

\section{$3^{\circ}$ colocado - Centro de Pesqui-} sas do HCPA: Inovando a gestão da pesquisa, por meio de laboratórios compartilhados

\section{Compartilhando esforços}

Por ser vinculado à Universidade Federal do Rio Grande do Sul, a pesquisa também faz parte da rotina do Hospital de Clínicas de Porto Alegre (HCPA), que desde de 2001, optou por unir esforços dentro da instituição para ampliar o desenvolvimento de estudos e experiências. Até então, o HCPA passou muitos anos aquém do seu potencial para realizar pesquisas devido à falta de estrutura que viabilizasse o uso racional das áreas e equipamentos do hospital.

"Os projetos de pesquisa desenvolviam-se nas áreas de atendimento a pacientes integrando-se à rotina do hospital, fato que dificultava os procedimentos de assistência a pesquisas e a adequada alocação de recursos. A dificuldade de realizar experimentos com animais é um exemplo claro. Sem estrutura, era necessário realizá-los fora da instituição", relembra o presidente do HCPA, Sérgio Pinto Machado.

\section{Em busca de soluções}

A partir da identificação das principais necessidades, uma equipe do HCPA

Sérgio Carlos Eduardo Pinto Machado, Themis Reverbel da Silveira, Luiz Lavinsky, José

Roberto Goldim, Rosane Paixão Schlatter

elaborou o projeto Inovando a Gestão da Pesquisa Por Meio de Laboratórios Compartilhados, que deu novo impulso às atividades de pesquisa da instituição. Com a implementação da iniciativa, o HCPA começou a racionalizar o uso dos equipamentos e do espaço físico, otimizando recursos, conseqüentemente. A principal característica desse tipo de gestão é o uso compartilhado. Qualquer projeto que ingresse no HCPA e necessite de condições básicas para seu desenvolvimento poderá utilizar a estrutura ali disponibilizada para projetos de pesquisa já existentes.

Para atender esse modelo, foi criado o Centro de Pesquisas, que hoje abriga, numa área de quatro mil metros quadrados, cinco laboratórios compartilhados: Unidade de Experimentação Animal,

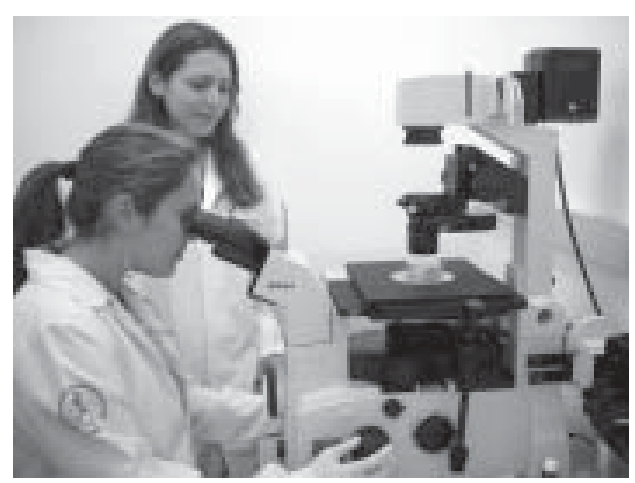

Laboratório de reprodução (Foto: arquivo HCPA) 
Laboratório de Patologia, Laboratório de Patologia Clínica, Centro de Terapia Gênica e Engenharia Biomédica. Há também os laboratórios temáticos, que possuem caráter temporário e auto-sustentável.

"Ao mesmo tempo, obtivemos maior integração e intercâmbio entre pesquisadores. Isso resultou em acréscimo de projetos multidisciplinares. Assim, em um único prédio, estamos desenvolvendo uma grande quantidade de linhas de investigação, dentro de variadas especialidades, com resultados reconhecidos nacional e internacionalmente", explica Machado.

Os resultados dessa iniciativa são comprovados pelas estatísticas do hospital. Em 2004, a média de pesquisas no laboratório de patologia, por exemplo, aumentou para 9, enquanto em 2002 era de apenas 3,7 pesquisas. Só no ano passado, foram estudados 1.367 animais, realizados 7.758 cirurgias ou procedimentos em animais de pequeno porte e estavam em atividade 271 pesquisadores. De 2003 a 2004, houve um aumento de $34,3 \%$ no número de exames realizados.

Para que o Centro de Pesquisas fosse viabilizado, foram investidos $\mathrm{R} \$ 2,7$ milhões para a construção da obra física, recurso proveniente do próprio HCPA e da Coordenação de Aperfeiçoamento de Pessoal de Nível Superior (CAPES), com a participação da Fundação de Amparo a Pesquisa do Rio Grande do Sul (FAPERGS).

\section{Portas abertas para a pesquisa}

A pesquisa sobre cirrose hepática em ratos da bióloga do HCPA, Úrsula Matte, talvez não existisse, se não fosse o compartilhamento dos laboratórios. A pesquisadora é uma das beneficiadas pelo projeto. "Antes da implementação do Centro de Pesquisa, eu não tinha nenhuma pesquisa com animais e agora são seis experiências nessa área. Pensávamos duas vezes antes de fazer experiências com animais, pois tínhamos que ver tudo, onde deixá-los, onde procurá-los", relata.

A bióloga lembra que a boa vontade de outras pessoas era a solução improvisada. "Tentávamos usar a estrutura do hospital, ou da Universidade Federal, numa condição pior, pois dependíamos da boa vontade das pessoas. Para fazer a análise bioquímica ou histológica era a mesma coisa: eu tinha que montar um laboratório

\section{"Antes da implementação desse projeto, eu não tinha nenhuma pesquisa com animais e agora são seis experiências nessa área”}

dentro de um algum setor da universidade ou do hospital, por exemplo".

Ela comenta também sobre outros benefícios do projeto e as portas que se abriram para a realização de estudos e pesquisas. "Essa experiência abre muitas possibilidades, porque nós temos condições de trabalhar com diferentes técnicas. Em um único laboratório, temos acesso a diferentes equipamentos em que podemos fazer análise histológica, análise bioquímica, o que propicia uma redução significativa de custos, pois eu já tenho essa estrutura montada", afirma Úrsula.

Outro aspecto positivo do compartilhamento dos laboratórios é o apoio qualificado de outros colegas. "Quando eu vou fazer uma experiência animal, por exemplo, técnicos me auxiliam, indicando a melhor maneira de utilizar os animais ou a melhor técnica a ser empregada naquela pesquisa", diz. 
De acordo com o presidente do HCPA, Sérgio Pinto Machado, os estudos desenvolvidos nos laboratórios do Centro de Pesquisas trazem, de forma crescente, importantes contribuições para a evolução dos conhecimentos em saúde, impulsionando avanços na prevenção, diagnóstico e tratamento de muitas doenças. "Ficamos contentes com a classificação do projeto no Concurso da ENAP, pois, para nós, isto significa o reconhecimento de sua importância social e nos estimula ainda mais a continuarmos neste caminho que faz do Hospital de Clínicas, também na área de pesquisa, um referencial público de alta confiabilidade", conclui Machado.

Outros finalistas do concurso

$4^{\circ}-\mathrm{O}$ novo olhar sobre a gestão de pessoas do setor público, na nova idade da democracia no Brasil (Diretoria de Gestão de Pessoas e Administração, Radiobrás)

$5^{\circ}$ - Programa GESAC - Governo Eletrônico - Serviço de Atendimento ao Cidadão (Secretaria de Telecomunicações - Departamento de Inclusão Digital, Ministério das Comunicações)

$6^{\circ}$ - Gestão estratégica de compras: otimização do pregão presencial (Hospital de Clínicas de Porto Alegre, Universidade Federal do Rio Grande do Sul)

$7^{\circ}$ - Modelo de gestão de capacitação da Presidência da República pool de capacitação (Diretoria de Recursos Humanos, Casa Civil da Presidência da República)

$8^{\circ}$ - Sistema de controle da arrecadação do Adicional ao Frete para Renovação da Marinha Mercante (Departamento do Fundo de Marinha Mercante, Ministério dos Transportes) 